\title{
Incidence of Type I diabetes mellitus in children and young adults in the province of Upper Austria, 1994-1996
}

\author{
B. Rami ${ }^{1}$, T. Waldhör ${ }^{2}$, E. Schober ${ }^{1}$ on behalf of the Diabetes Working Group of Upper Austria* \\ ${ }^{1}$ Department of Paediatrics, University of Vienna, Vienna, Austria \\ ${ }^{2}$ Institute for Cancer Research, Department for Epidemiology, University of Vienna, Vienna, Austria
}

\section{Abstract}

Aim/hypothesis. The aim of our study was to determine the incidence rate of Type I (insulin-dependent) diabetes mellitus in the 15-30 years age group in a well-defined province in Austria and to compare this with the incidence rate of childhood-onset diabetes mellitus in the age group 0-15 over a 3-year period.

Methods. Incident cases of Type I diabetes were reported by the local departments of medicine and paediatrics prospectively to the Austrian Diabetes incidence registry. Completeness of ascertainment was calculated by the capture-recapture method.

Results. The incidence rates per 100000 person-years for Type I diabetes in the Austrian province of Upper Austria were 8.99 (7.02-11.4, 95\%-CI) for the $0-15$ years age group and $7.1(5.5-9.0,95 \%-C I)$ for the 15-30 years age group. The estimated completeness of ascertainment was 93\% (89.0-97.1\%, 95\%CI) for children and $87 \%(84.1-89.9 \%, 95 \%-C I)$ for young adults. Sex differences were evident in young adults, with a 1.6-fold increased risk in males older than 15 years and 2.2-fold increased risk in men over 20 years of age.

Conclusion/interpretation. Our study shows that the incidence rate of Type I diabetes in Austria after the age of 15 years is similar to the incidence rate in childhood. An unexplained male predominance in patients older than 20 years could be observed as in several other countries. [Diabetologia (2001) 44 [Suppl 3]: B 45-B 47]

Keywords Diabetes mellitus Type I, incidence, young adult, Austria.
The incidence rates of Type I (insulin-dependent) diabetes mellitus show a large geographic and temporal variation [1-3]. Most incidence studies have been performed in the 0-14 years age-group [1-7] and only a few registries include the group over 15 years of age [8-14].

Some of the regional differences in the frequency of the disease could be due to differences in the age of onset between the countries, with a younger age at diagnosis in the high-risk countries and an older age at diagnosis in the low-risk countries. It could be that the increase observed in incidence of childhood-

Corresponding author: Dr. Edith Schober, University Children's Hospital, Währinger Gürtel 18-20, 1090 Vienna, Austria

* see Acknowledgements onset diabetes in several regions [5, 6, 15-17] is due to a shift of the incidence peak in the younger age group $[5,7,18,19]$.

Our study examined the incidence rate of Type I diabetes in the province of Upper Austria in the age group 15-29 years during 1994-1996 and compared it with the incidence rate in children of the same province.

\section{Subjects and methods}

Population and geographical data. Upper Austria is one of the nine provinces of Austria with an area of 12000 square kilometres. Population data were obtained from the Austrian Central Statistic Office in Vienna (National Census 1990). In the study period (01.01.1994-31.12.1996) the province of Upper Austria had 536847 inhabitants aged $0-<30$ years out of a total population of 1377902 inhabitants. 
Table 1. Annual incidence rates (per 100000 person-years) of Type I diabetes in Upper Austria $1994-1996$ between 0 and 29 years grouped according to age and sex

\begin{tabular}{|c|c|c|c|c|c|c|}
\hline \multirow{2}{*}{$\begin{array}{l}\text { Age } \\
\text { (years) }\end{array}$} & \multicolumn{2}{|l|}{ Males } & \multicolumn{2}{|l|}{ Females } & \multicolumn{2}{|l|}{ Total } \\
\hline & $\begin{array}{l}\text { Patients/ } \\
\text { person-years at risk }\end{array}$ & $\begin{array}{l}\text { Incidence rate } \\
(95 \%-C I)\end{array}$ & $\begin{array}{l}\text { Patients/ } \\
\text { person-years at risk }\end{array}$ & $\begin{array}{l}\text { Incidence rate } \\
(95 \%-C I)\end{array}$ & $\begin{array}{l}\text { Patients/ } \\
\text { person-years at risk }\end{array}$ & $\begin{array}{l}\text { Incidence rate } \\
(95 \%-C I)\end{array}$ \\
\hline $5-<10$ & $12 / 133224$ & $9.0(4.6-15.7)$ & $14 / 127560$ & $10.0(6.0-18.4)$ & $26 / 260784$ & $9.9(6.5-14.6)$ \\
\hline $10-<15$ & $14 / 136122$ & $10.3(5.6-17.3)$ & $16 / 130233$ & $12.3(7.0-19.9)$ & $30 / 266355$ & $11.3(7.6-11.3)$ \\
\hline $15-<20$ & $14 / 128070$ & $10.9(6.0-18.3)$ & $13 / 122001$ & $10.7(8.7-18.2)$ & $27 / 250071$ & $10.0(7.1-15.7)$ \\
\hline $20-<25$ & $11 / 157092$ & $7.0(3.5-12.5)$ & $4 / 150354$ & $2.7(0.7-6.8)$ & $15 / 307446$ & $4.9(2.7-8.0)$ \\
\hline
\end{tabular}

Data collection and ascertainment. A prospective diabetes incidence surveillance system has been set up in Upper Austria. All 8 paediatric and all 25 medical departments agreed to participate, although 7 medical departments of another specialisation (cardiology, nephrology etc.) in larger hospitals reported that they immediately transfer newly diagnosed diabetic patients in the under 50 years age group to the specialised diabetic medical department in the same hospital. All newly diagnosed diabetic patients were reported to the study centre at least every 6 months using a standardised registration form.

The following data were recorded: name or initials, sex, date of birth, place of residence (postal code), date of first insulin injection, blood glucose and body weight as well as whether the patient was on continuous insulin treatment when leaving the hospital and considered to have Type I diabetes by the local diabetologist. Women with gestational diabetes and patients with suspected Type II or secondary diabetes were excluded from the analysis.

The completeness of the primary ascertainment was validated by the membership list of the Austrian Diabetes Association (OODV) for young adult patients in combination with the diabetes camp participation lists for children as the secondary data source. The Austrian Diabetes Association is very active, advertising in medical magazines, in private practices, television and newspapers. The estimated completeness of ascertainment was $93 \%(89.0-97.1 \%, 95 \%-C I)$ for children and $87 \%(84.1-89.9 \%, 95 \%-C I)$ for young adults $(15-<30$ years). The estimated completeness of ascertainment was $86 \%$ $(84,3-88,0 \%, 95 \%-C I)$ for men and $87 \%(85,2-89.9 \%, 95 \%$ CI) for women in the age group of 20 years or older.

Statistical methods. For the age and sex specific incidence rates, confidence intervals (CIs) were estimated assuming a Poisson distribution of the cases. The influence of sex on the incidence rates was tested by means of a Poisson regression model in SAS (SAS/STAT User's Guide, Version 6, Fourth Edition, Volume 2. Cary, N.C., USA: SAS Institute, 1989), where the variable age was included in addition to sex. In one model age was coded as categorical, in a second model age was added as a linear as well as a quadratic term. Completeness of ascertainment was estimated by the capture-recapture method [20], which assumes ascertainment of the same catchment population by using a combination of independent data sources.

\section{Results}

During the three-year period 1994-1996, our study identified 137 newly diagnosed patients with Type I diabetes mellitus in the $0-30$ years age group in the whole province of Upper Austria (ascertainment corrected). A total of 73 patients were males and 64 were females.

Table 1 gives the annual incidence rates of Type I diabetes between 0 and 29 years for each age group and sex.

The mean incidence for the $0-15$ years age group was 8.99 (7.02-11.4,95\%-CI) and 7.1 (5.5-9.0, 95\%CI) for the 15-30 years age group. Altogether 52\% of the newly diagnosed patients were younger and $48 \%$ were older than 15 years.

In children, the male-to-female ratio was $0.82: 1$, whereas in adolescents and young adults the maleto-female ratio was $1.64: 1$. The male predominance was most obvious in the age group of 20 years or older (men: women $=2.25: 1$ ).

The poisson regression model showed a statistically significant interaction term between sex-squared and age-squared. This result was confirmed when modelling the rates separately by sex. In males no significant age trend could be observed. In females a significant $(p=0.023)$ squared age effect was estimated pointing to a non-linear increase in incidence for this group.

\section{Discussion}

Our study compares the incidence rates between childhood-onset Type I diabetes and newly diagnosed young adults in the same province during the same period by the same method of registration [4]. Austria is a country with an intermediate but steadily increasing risk for Type I diabetes in children younger than 15 years of age [16]. In this study we observed the peak incidence to be about 10 per 100000 for both sexes between the age of 5 and 20 years.

For males we found an almost similar incidence rate in the older age cohort as in the childhood cohort. The numbers could still be an underestimate as all patients not initially put on continuous insulin therapy were excluded and follow-up of uncertain cases was not possible. Similar high proportions of incident rates in young adults have been reported in 
Italy [12], in Poland [13], Belgium [11], Norway [9] and Sweden [10].

In accordance with several other studies $[9-12,14]$, we found a striking male predominance in the age group 20 years or older, whereas during childhood and adolescence the male-to-female ratio was almost the same as the background population. As the completeness of ascertainment was similar for both sexes, we believe that the observed difference is not due to underreporting of female patients. The reason for the excess risk of young adult men is not clear but is found with few exceptions $[13,21]$ in all registries extending their ascertainment to the age cohort above the age of 20 years. Hormonal or genetic factors could influence the susceptibility of young adult males to environmental triggers. A recent study analysing the Type I diabetes mellitus susceptibility haplotypes in medium and high-incidence populations observed a bias in male incidence restricted to $D R 3 / X$ [22]. In the Belgian registry, the frequency of genotypes without either $H L A-D Q$ risk haplotypes was higher in the older patient group [11] indicating genetic heterogeneity of the disease varying with age at onset.

In conclusion, we observed a clear sex difference in the risk for Type I diabetes in young adults over 20 years of age, with a twofold risk in men. The overall incidence rate between 15 and 30 years of age is unexpectedly high for Austria. The registration of this age cohort should be continued to obtain more information on time trends because the Swedish and the Finnish registries showed a decrease of the incidence in young adults $[18,19]$ with an increased in childhood-onset diabetes during the same period $[5$, 7].

Acknowledgements. This project was kindly supported by Novo Nordisk Austria and Eli. Lilly Austria. We would like to thank the members of the Upper Austrian Diabetes Working Group for their co-operation: C. Auer, K. Täuber, R.M. Dejaco, A. Holzinger, J. Ecker, G. Remsa, B. Schneeweiss, F. Leisch, G. Biesebach, A. Gegenhuber, K. Lenz, F. Pilshofer, P. Kühn, P. Langmayr, J Nesser, H. K. Stummvoll, F. Renner, G. Lobmeier, W. Schmid, CH. Haider, J. Walkobinger, J. Froschauer, R. Leeb, M. Federl, R. Haidinger, L. Schiller, Scherfler, W. Fereberger, St. Allinger, P. Knoflach, O. Pachinger, W. Reiterer.

\section{References}

1. Deri Group (1988) Geographic patterns of childhood insulin dependent diabetes mellitus. Diabetes 37: 1113-1119

2. Green A, Gale EAM, Patterson CC for the EURODIAB ACE Group (1992) Incidence of childhood - onset insulin-dependent diabetes mellitus: the EURODIAB ACE study. Lancet 339: 905-909

3. Karvonen M, Tuomilehto J, Libman I, LaPorte RE for the WHO DIAMOND Project Study Group (1993) A review of the recent epidemiological data on the world-wide incidence of Type I (insulin dependent) diabetes mellitus. Diabetologia 36: $70-76$
4. Schober E, Frisch H (1988) Incidence of childhood diabetes mellitus in Austria 1979-1984. Acta Paediatr Scand 77: 299-302

5. Nyström L, Dahlquist G, Rewers M, Wall S (1990) The Swedish Childhood Diabetes study. An analysis of the temporal variation in diabetes incidence 1978-1987. Int J Epidemiol 19: 141-146

6. DERI Group (1990) Secular trends in incidence of childhood IDDM in10 countries. Diabetes 39: 858-864

7. Tuomilehto J, Rewers M, Reunanen A et al. (1991) Increasing trend in Type I (insulin dependent) diabetes mellitus in childhood in Finland. Analysis of age, calendar time and birth cohort effects during 1965-1984. Diabetologia 34: 282-287

8. Christau B, Kromann H, Christy M, Ortved M, Nerup J (1979) Incidence of insulin dependent diabetes mellitus (0-29 years at onset) in Denmark. Acta Med Scand 624 [Suppl 1]: 54-60

9. Joner G, Sovik O (1991) The incidence of Type I (insulin dependent)diabetes mellitus 15-29 years in Norway 1978-1982. Diabetologia 34: 271-274

10. Blohme G, Nyström L, Arnqvist HJ et al. (1992) Male predominance of Type I (insulin-dependent) diabetes mellitus in young adults: results from a 5 year prospective nation-wide study of the 15-34 year age group in Sweden. Diabetologia 35: 56-62

11. Vandewalle CH, Coeckelbergh MI, De Leeuw ICH et al. The Belgian Diabetes Registry (1997) Epidemiology, clinical aspects and biology of IDDM Patients under age 40 years. Diabetes Care 20: 1556-1561

12. Bruno G, Merletti F, De Salvia A, Lezo A, Arcari R, Pagano G on behalf of the Piedmont study Group for Diabetes Epidemiology (1997) Comparison of Incidence of Insulin-dependent Diabetes Mellitus in Children and Young adults in the Province of Turin, Italy 1984-91. Diabet Med 14: 964-969

13. Gryzwa MA, Sobel AK (1995) Incidence of IDDM in the province of Rzeszow, Poland, 0 to 29 year old age group, 1980-1992. Diabetes Care 18: 542-544

14. Ostraukas R, Zalinkevicius R, Norkus and the Lituanian Epidemiology Diabetes Study Group(1999) Incidence and prevalence of Type I diabetes mellitus among adult population in Lithuania 1991-1997. Diabetologia 42 [Suppl 1]: A86 (Abstract)

15. Schoenle EJ, Molinari L, Bagot M, Semandeni S, Wiesendanger M (1994) Epidemiology of IDDM in Switzerland. Increasing incidence rate and urban-rural differences in Swiss men born 1948-1972. Diabetes Care 17: 955-960

16. Schober E, Schneider U, Waldhör Th, Tuomilehto J and Austrian Diabetes Incidence Study Group (1995) Increasing incidence of IDDM in Austrian children - a nation-wide study 1979-1993. Diabetes Care 18: 1280-1283

17. Ruwaard D, Hirasing RA, Reeser HM, van Buuren S, Bakker K, Heine RJ ( 1994) Increasing incidence of Type I diabetes in the Netherlands. The second nation-wide study among children under 20 years of age. Diabetes Care 17: 599-601

18. Nyström L, Arnqvist H, Blohme G et al. (1998) The incidence of diabetes mellitus in the age group 15-34 years in Sweden is decreasing. Diabetologia 40 [Suppl 1]: A82 (Abstract)

19. Jormanainen V, Korpela M, Tuomilehto J, Sahi T (1997) Prevalence of insulin dependent diabetes mellitus among young Finnish males in 1975-1995. Diabetologia 40 [Suppl 1]: A65 (Abstract)

20. LaPorte RE, McCarty D, Bruno G, Tajima N, Baba S (1993) Counting diabetes in the next millennium: Application of capture-recapture technology. Diabetes Care 16: 528-534

21. Gorham ED, Garland FC, Barrett-Connor E, Garland C, Wingard DL, Pugh WM (1993) Incidence of insulin-dependent diabetes mellitus in young adults: experience of 1,587,630 US navy enlisted personnel. Am J Epidemiol 138: 984-987

22. Cucca F, Goy JV, Kawaguchi Y et al. (1998) A male-female bias in Type I diabetes and linkage to chromosome $\mathrm{Xp}$ in $\mathrm{MHC}$ HLA-DR3-positive patients. Nat Genet 19: 301-302 